\title{
Next generation of Eurocode 8, masonry chapter
}

\author{
S. Lu
}

Vienna University of Technology, Vienna, Austria

K. Beyer

EPFL Lausanne, Lausanne, Switzerland

V. Bosiljkov

University of Ljubljana, Ljubljana, Slovenia

C. Butenweg

RWTH Aachen, Aachen, Germany

D. D'Ayala

University College London, London, UK

H. Degee

University Hasselt, Hasselt, Belgium

M. Gams

ZAG, Ljubljana, Slovenia

\section{J. Klouda}

Technical and Test Institute for Construction Prague, Brno, Czech Republic

S. Lagomarsino

University of Genoa, Genoa, Italy

\section{A. Penna}

University of Pavia, Pavia, Italy

N. Mojsilovic

ETH Zurich, Zurich, Switzerland

F. da Porto

University of Padua, Padua, Italy

\section{Sorrentino}

Sapienza University of Rome, Rome, Italy

E. Vintzileou

NTU Athens, Athens, Greece

\begin{abstract}
This paper describes the procedure on the evaluation of the masonry chapter for the next generation of Eurocode 8, the European Standard for earthquake-resistant design.

In CEN, TC 250/SC8, working group WG 1 has been established to support the subcommittee on the topic of masonry on both design of new structures (EN1998-1) and assessment of existing structures (EN1998-3).

The aim is to elaborate suggestions for amendments which fit the current state of the art in masonry and earthquake-resistant design. Focus will be on modelling, simplified methods, linear-analysis ( $q$-values, overstrength-values), nonlinear procedures, out-of-plane design as well as on clearer definition of limit
\end{abstract}


states. Beside these, topics related to general material properties, reinforced masonry, confined masonry, mixed structures and non-structural infills will be covered too. This paper presents the preliminary work and results up to the submission date.

\section{INTRODUCTION}

\subsection{Introduction}

In CEN, the European Committee for Standardization, the Sub-Committee SC8, of the technical committee TC250 for "Structural Eurocodes", dealing with the EN 1998 series, "Design of structures for earthquake resistance" received the mandate to develop the next generation of EN 1998 series. Working under the direction of the CEN/TC 250, funded Project Teams will undertake the core drafting work. As support for the broad field of masonry and seismic engineering, working group WG1 has been formed under CEN TC250/SC8 to support the Project Teams in this field.

\subsection{Fields of amendment}

In general, WG1 identified the following topics, which will be focused on during their work:

general reorganization of the code-(i) moving from a code whose principles are strongly influenced by concrete and steel design concepts towards a code whose general principles are suitable for all materials including masonry (ii) non-linear analysis, procedure, displacement demand; (iii) in plane capacity for non-linear analysis; (iv) modelling (slabs, spandrels, lintels); (v) q-values, overstrength values; (vi) simplified masonry, tables and rules; (vii) out of plane design; (viii) clearer and more consistent definition of limit states (damage limit state, life safety, collapse); (ix) reinforced masonry (including also horizontal reinforcement only); (x) confined masonry; (xi) mixed structures (RC and masonry); (xii) non structural infills; (masonry dry walls, etc., out of plane) and (xiii) material properties; (mean strength values for nonlinear analysis, robustness, head and bed joint configurations).

\section{NONLINEAR ANALYSIS PROCEDURES}

Since the late 1970s nonlinear static analysis has been used in seismic assessment and design of masonry structures. As can be easily verified, linear analysis may be very overconservative when applied to masonry structures, which, instead, typically show a strongly nonlinear behaviour since the first stages of the structural response.

For these reasons, in spite of the attempts to better define behaviour factors, including overstrength (Magenes, 2006), for linear analysis and reformulating rules for the design of simple masonry build- ings, pushover analysis is widely used in assessment and design of masonry buildings in several moderate to high seismicity countries in Europe.

This diffusion and use of pushover analysis for masonry structures (much more common than for concrete and steel structures) calls for a general revision of the procedure currently proposed in EC8, which needs further specifications to be fully applicable to masonry buildings (e.g. displacement/drift limits) as it is for example the procedure proposed in the Italian Building code (NTC, 2008) and its commentary.

Several aspects, also related to modelling requirements, definition of capacity and simplified evaluation of the displacement demand, need to be considered. They are summarised in the following subsections.

\subsection{Pushover analysis procedure}

A general revision of the pushover analysis procedure includes the review of the applicability conditions of pushover analysis for design and assessment, which may be related to the structural regularity and the characteristics of the horizontal diaphragms. Also, the definition of a standard pushover analysis algorithm (e.g. displacement control with constant load pattern) and possible alternatives (e.g. adaptive, multi-modal) could be considered.

A suitable procedure for converting the pushover curve into a bilinear capacity curve for an equivalent single-degree-of-freedom system needs to be specifically defined for the case of masonry structures.

Moreover, the simplified formulae for the determination of the displacement demand which are currently reported in EC8 (Fajfar, 2000) were developed for structural systems with periods of vibration longer than those typical of masonry structures and were characterized by different hysteretic behaviours. For these reasons, possible modifications to the current formulae will be considered (Graziotti, 2013).

Displacement-based safety checks also require the definition of appropriate displacement limit states, based on member drift capacity and/or alternative criteria for the definition of global limit states.

\subsection{Structural models for pushover analysis}

Spatial building models based on the equivalent frame approach will be probably considered as the reference models for the analysis of masonry buildings. Simpler models may be still accepted for 
specific cases and specific limitations; the use of more sophisticated modelling strategies could also be an option. Minimum model requirements and limitations of the applicability of each modelling solution need to be considered.

For equivalent-frame models, specific requirements for structural member elements (nonlinear frame models representing piers and spandrels) will include consistency with appropriate definitions of force (strength criteria) and displacement capacity. Indications for modelling floor and roof diaphragms (inplane/out-of-plane stiffness) will be also evaluated.

Advanced modelling strategies (e.g. FEM or discrete element modelling), to be mainly adopted for structures falling outside the range of applicability of equivalent frame models, may require specific benchmarking of modelling and analysis results for meeting acceptability conditions.

\subsection{Other issues on nonlinear analysis}

Other topics are covered by the sub-working group dealing with nonlinear analysis of masonry buildings:

- Issues related to pushover analysis considering different loading directions;

- Procedures for nonlinear time history analysis, including the definition of minimum model requirements for dynamic analysis and the definition of limit states;

- Nonlinear analysis procedures for buildings with mixed/combined masonry and non-masonry structures;

- Issues related to convergence of nonlinear analysis and use of sensitivity studies.

\section{FORCE AND DISPLACEMENT CAPACITY OF PIERS AND SPANDRELS}

The current version of Eurocode EN 1998-3 (CEN, 2005) estimates the drift capacity of unreinforced masonry piers based on the failure mode (shear vs flexure) and the shear span ratio $H_{0} / L$ where $H_{0}$ is the height of zero moment and $L$ the wall length:

$$
\begin{array}{ll}
\text { Shear failure: } & \delta_{S D}=0.4 \% \\
\text { Flexural failure: } & \delta_{S D}=0.8 \% \cdot \frac{H_{0}}{L}
\end{array}
$$

Equations (1) and (2) give the drift capacities for the limit state "Significant Damage" (SD). To obtain the drift capacity at near collapse limit state, $\mathrm{NC}$, the drift capacities of Equations (1) and (2) are multiplied by a factor 4/3 (EN 1998-1; CEN, 2004). Other design codes use similar approaches (Petry and Beyer 2014, Snoj 2014, Kržan et al.
2015). Current codes do not distinguish between the type of the masonry when assessing the drift capacity and assign all masonry types from modern brick masonry to ancient stone masonry the same drift capacity. Furthermore, current codes do not provide guidelines for the deformation capacity of unreinforced masonry spandrels.

The definition of the deformation capacity of piers and spandrels calls therefore for a general revision in the version of the code. It is suggested that in particular the following points should be addressed.

\subsection{Deformation capacity of piers}

At present, the drift capacity is defined in terms of interstorey drift where it is computed as the difference in horizontal displacements at two successive storeys divided by the storey height. A revision should take into account the outcomes from numerous research results that clarify the influence of vertical stresses, element aspect ratio and boundary conditions on the different performance limits for different types of the masonry. Beside shear and flexural modes of failure a mixed type (governed by aspect ratio) will be introduced for historic types of masonry. For this type of masonry additional performance limits as well as safety factors will be set depending on its texture and morphology. For some classes of masonry additional performance limits will enable multilinear idealization of structural element response.

The background of the current drift capacity equations is not known to the authors. In particular, it is not known to which type of masonry the drift limits apply, which experimental dataset was used for the validation of these drifts and which fractile value they represent. For the next generation of Eurocode 8 it is desirable that the derivation of any new drift capacity equations be made transparent. This applies in particular to the following steps:

i. Definition of a unified way to derive performance limits from quasi-static cyclic tests.

ii. Collection of data bases for different types of masonry,

iii. Review of existing drift capacity equations for different performance limit states,

iv. Proposal of new deformation capacity equations for use in codes,

v. Introduction of a safety factor for displacement capacities.

\subsection{Deformation capacities of spandrels}

Spandrels have long been recognised to strongly influence the force-displacement response of unreinforced masonry buildings (Chen, Moon, \& 
Yi, 2008; Magenes, 2000). The current version of Eurocode EN 1998-1 (CEN, 2004), however, does not contain any information on spandrels, which arose from the absence of experimental tests on spandrels. Over the last decade, such test results have become available (Amadio, Gattesco, Dudine, Franceschinis, \& Rinaldin, 2012; Beyer \& Dazio, 2012a, 2012b; Graziotti, 2013). Although they are very scarce when compared to tests on piers, the tests allow mechanical and numerical models to be validated. The New Zealand Guideline for the Seismic Assessment of Buildings was the first international code to include the definition of the complete force-displacement response of spandrels. ASCE 41 (ASCE/SEI, 2013) is currently under revision and is likely to adopt a similar path. It is recommended that a revision of Eurocode 8 adopts a similar approach. This comprises:

i. Definition of deformation capacity,

ii. Review of existing tests on masonry spandrels,

iii. In collaboration with Working group "Modelling", proposal of the force-rotation response of spandrels, i.e., the effective stiffness of the spandrel, the strength of the spandrel for the peak and residual strength regime and the corresponding rotation limits.

\subsection{Effective stiffness of masonry}

One of the most challenging and still not satisfactorily solved issues in the seismic design of structural masonry is the assessment of the stiffness of shear walls. Determining the correct stiffness is of utmost importance for the deformationbased design of masonry structures. In general, the response of masonry walls subjected to cyclic shear is nonlinear and dependent upon several parameters, e.g. the level of the pre-compression applied to the shear wall, boundary conditions etc. Moreover, the reduction in both strength and stiffness of masonry can be observed during cycling, see e.g. Mojsilović (2014). Usually, the hysteresis curve is chosen to represent the load-deformation characteristics for the evaluation of the deformation capacity of masonry. This relationship can be modelled by a (bilinear) linear-elastic ideal-plastic curve. The first portion of this curve is determined by the effective stiffness, $K_{\text {eff }}$

In general, the effective stiffness, is a complex parameter and difficult to determine. For practical applications, it is usually adopted as a certain percentage (usually $50 \%$ ) of the elastic stiffness, $K_{e l}$. Elastic stiffness is usually calculated based on the elastic beam theory incorporating shear deformation. Furthermore, the masonry material mechanical characteristics involved in this calculation are rarely determined through material tests, but are

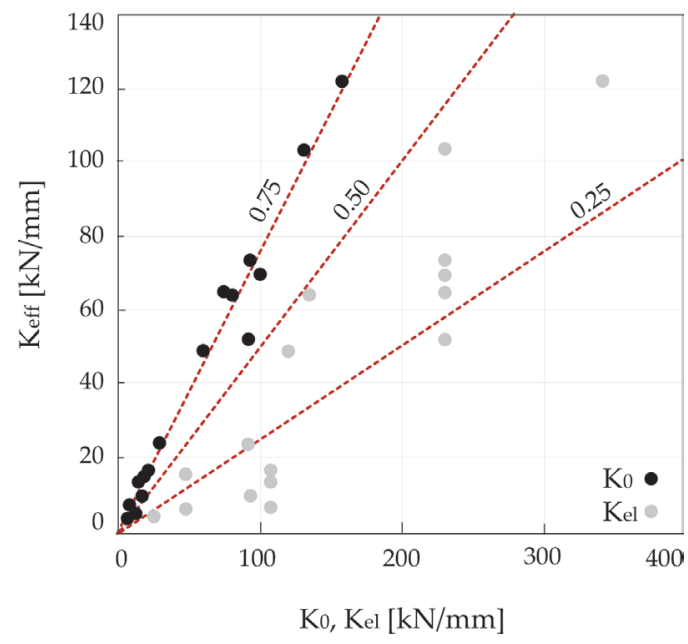

Figure 1. Stiffness comparisons.

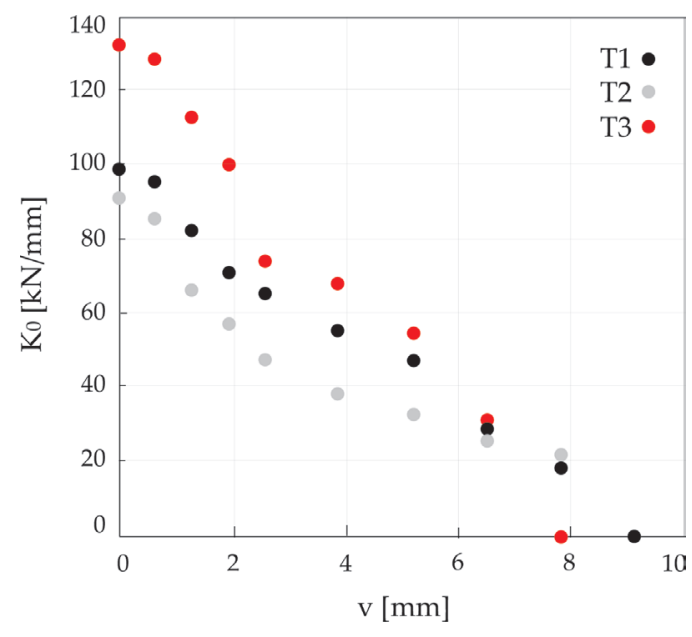

Figure 2. Stiffness degradation.

rather chosen based on experience or adopted from Structural Code provisions and recommendations.

In the case where the experimental data from cyclic tests is available, the tangent stiffness, $K_{0}$, evaluated as the slope of the line connecting the positive and negative extreme points of the first hysteresis loop, i.e. the loop corresponding to the first applied displacement cycle, see also Salmanpour et al. (2015) could be used to obtain the effective stiffness. However, as shown in Figure 1, the ratio between the tangent stiffness, $K_{0}$, and the effective stiffness as well as between the elastic stiffness and the effective stiffness for clay block masonry walls, is scattered and the latter ratio is, in most cases, much smaller than 0.5 . 
Furthermore, as can be clearly seen from the hysteretic behaviour of the masonry walls a significant degradation of stiffness $K_{0}$ during cyclic loading can be observed. Figure 2 shows exemplarily the stiffness degradation for three tests of the Series T (Salmanpour et al. 2015).

\section{Q-VALUES (BEHAVIOUR FACTORS), OVERSTRENGTH VALUES}

The use of linear methods of analysis and strength based design with a behaviour factor (q-factor) is known to give rise to many problems and inconsistencies in design/assessment of masonry buildings, possibly more than for other structural types (Magenes, 2006). The main reason for these problems lies in the fact that in the definition of the q-factor an overstrength ratio (OSR) should be accounted for, as a consequence of the fact that the attainment of the strength capacity in a structural member or section can be reached in a linear analysis for levels of seismic loading that are well below those corresponding to the seismic capacity of the structural system, The main problem to be overcome is that such OSR strongly depends on the structural layout of the building. For reinforced masonry it is possible, in the new design of buildings, to vary the strength in members by varying the reinforcement: in URM buildings the strength of walls is essentially a result of the geometry, which is governed to a great extent by architectural needs, and of how the floor systems distribute the gravity loads to the walls. As a result, the OSR can vary widely from building to building (and even for the same building depending on the direction of seismic loading).

Currently, in the Italian structural design code (NTC 2008) the concept of overstrength ratio is already implemented: nevertheless a more general approach should be sought for EC8 to cover the wide spectrum of structural configurations that can be met in the different European countries.

\section{SIMPLIFIED TABLES AND RULES}

The current version of EN 1998-1 (CEN, 2004) already includes a chapter on how to design masonry structures by purely considering geometric aspects, such as shear wall area percentages in relation to ground floor footprint area. Obviously this table is limited by peak ground acceleration and maximum applicable storey numbers. The idea here is to design simple masonry buildings, such as single family houses, without a highly sophisticated numerical analysis.

Nevertheless, the values in the current table should be subjected to revision, in the light of the more recent results of nonlinear analyses. The plan is to reorganise and redefine this table using conservative but realistic behaviour factors, overstrength ratios, as well as the results of nonlinear analyses.

The aim is to present a conservative but applicable simplified method with shear wall area tables for practical engineers in case of simple masonry buildings.

\section{NON STRUCTURAL INFILLS}

Problems of Non Structural Components and Systems (NSCS) are more widespread and complicated than Non Structural Masonry Infills (NSMI), and are bound also to constructions other than Masonry: that is why this issue will be covered by subgroup SWP4-1998-1 for Non Structural Masonry Infills only - and not as it is organised in ISO 13033.

In current European standard EN 1998-1 (CEN, 2004), the problem of NSCS is not solved in the complex form, and that of NSMI is mentioned only. In the case of simple masonry buildings design, where a full seismic analysis is not requested, the problem of NSMI is not mentioned at all. In other cases, e.g. in multi-storey buildings with different types of framed construction (either in the nonstructural external walls or in their external layers), the criteria for design and construction such NSMIs should be evaluated and commented upon in the new version of the Standard; at least in sections 4.2.2, 4.3.5, 4.3.6, 5.7 and 5.9, respectively.

\subsection{Fields of Amendment}

- Non-structural masonry enclosures and partitions (variety of masonry types)

- Non-structural internal masonry infill walls (not serving as a part of a structural system of building)

- Non-structural external masonry infill walls, external leafs of multi-layer masonry walls and their connection / anchoring against earthquake motions

It will be necessary to recommend specific rules about the overall effect of masonry infills on seismic performance of building systems, bring attention to local effects on structural frames of different types and materials (for 2-storey and multi-storey buildings), their influence when combined with frequently used open ground storeys, the relevance of their distribution in plan and along the height of the building, etc.

Special topic of so called "dry masonry" and the influence of the out-of-plane effects on nonstructural infills will be mentioned, too. 


\section{MATERIAL PROPERTIES}

One of the first steps to be performed (which is already well under way) is the assembly of a proper database, which will serve for validation of proposed new (or modified) models and equations. The database will be made public, but will not be part of the code.

\section{SUMMARY}

The goal of WG1 is to hand over to TC250/SC8 its results and findings by 2018 , as a discussion base and further as recommendations for the next generation of the Eurocode by 2020 .

Finally it needs to be mentioned that all WG members are performing their work on an entirely voluntary basis.

\section{REFERENCES}

Amadio, C., Gattesco, N., Dudine, A., Franceschinis, R., \& Rinaldin, G. (2012). Structural performance of spandrels in stone masonry buildings. In 15th World Conference on Earthquake Engineering. Lisbon, Portugal.

ASCE/SEI. (2013). ASCE 41-13: Seismic evaluation and retrofit of buildings. Reston, Virginia, USA.

Beyer, K., \& Dazio, A. (2012a). Quasi-Static Cyclic Tests on Masonry Spandrels. Earthquake Spectra, 28(3), 907-929. http://doi.org/10.1193/1.4000063

Beyer, K., \& Dazio, A. (2012b). Quasi-static monotonic and cyclic tests on composite spandrels. Earthquake Spectra, 28(3), 885-906. http://doi.org/10.1193/1.4000058.

CEN (2004). Eurocode 8: Design of structures for earthquake resistance, Part 1: General rules, seismic actions and rules for buildings. Brussels, Belgium.
CEN. (2005). Eurocode 8: Design of structures for earthquake resistance, Part 3: Assessmemt and retrofitting of buildings. Brussels, Belgium.

Chen, S.-Y., Moon, F.L., \& Yi, T. (2008). A macroelement for the nonlinear analysis of in-plane unreinforced masonry piers. Engineering Structures, 30(8), 22422252. http://doi.org/10.1016/j.engstruct.2007.12.001

Graziotti,F.(2013). Contribution towards a displacementbased seismic assessment of masonry structures.

Kržan, M, Gostič, S., Cattari, S., Bosiljkov, V. (2015). Acquiring reference parameters of masonry for the structural performance analysis of historical buildings. Bulletin of earthquake engineering, 13(1), 203-236,.

Magenes, G. (2000). A method for pushover analysis in seismic assessment of masonry buildings. In Proceedings of the 12 World Conference on Earthquake Engineering (pp. 1-8). Auckland, New Zealand. Retrieved from http://www.iitk.ac.in/nicee/wcee/article/1866.pdf.

Magenes, G. (2006). Masonry building design in seismic areas. Recent experiences and prospect from a European standpoint, Proc 1st Europ Conf on Earthq Eng. and Seism \& 13th ECEE \& 30th general ass of ESC, Geneva, Switzerland, 3-8 Sept 2006, Keynote 9.

Mojsilović, N. (20144). Assessment of the Unreinforced Masonry Shear Wall Stiffness. In Proceedings of International Conference on Construction Materials and Structures, Johannesburg, South Africa. pp. $1157-1163$.

NTC 2008 (2008), Norme tecniche per le costruzioni" D.M. 14 Gennaio 2008.

Petry, S., \& Beyer, K. (2014). Influence of boundary conditions and size effect on the drift capacity of URM walls. Engineering Structures, 65, 76-88. http://doi. org/10.1016/j.engstruct.2014.01.048.

Salmanpour, A.H., Mojsilović, N. \& Schwartz J. (2015). Displacement capacity of contemporary unreinforced masonry walls: An experimental study. Engineering Structures, 89, 1-16.

Snoj J. (2014) Seismic risk assessment of masonry buildings, PhD Thesis, University of Ljubljana, Faculty of Civ. and Geo. Eng. 